\title{
Diálogo satírico de don Quijote y Sancho Panza sobre los males de la Nueva España (siglo XVIII)
}

\author{
MARÍA JosÉ RodILla*
}

\section{Introducción}

\section{El quiJote en Nueva España}

Hasta el año de festejos cervantinos, 2005, en el que se reveló el hallazgo en el Archivo General de la Nación de unos documentos rescatados del ramo de la Inquisición, que daban cuenta de 5 ejemplares llegados en septiembre de 1605 a bordo de la goleta La Encarnación ${ }^{1}$, se creía que el primer ejemplar del Quijote había llegado a la Nueva España de la mano de Mateo Alemán, quien desembarcó en 1608 en San Juan de Ulúa. El Quijote era entonces un libro prohibido, no en España, pero sí para ser importado a Indias, a donde sólo podían llegar libros piadosos y de leyes, pero no de entretenimiento, por disposiciones hechas en 1531 y 1534 . La aduana inquisitorial lo decomisó de su equipaje, pero la intervención del fraile dominico, luego arzobispo y virrey de México, Fray García Guerra, a quien Alemán había conocido en la travesía, logró que le devolvieran el libro. A pesar de las prohibiciones, se sabe, según nos cuenta Irving Leonard, que sacaban las impresiones del Quijote precipitadamente de las prensas para enviarlas a Sevilla, con el fin de que no perdieran la salida de las flotas anuales ${ }^{2}$.

Pero no sólo llegaban los libros; inmediatamente, amo y escudero empezaron a ganar fama en fiestas y mascaradas en las que salían como personajes

* Universidad Autónoma Metropolitana-Iztapalapa.

1. «Qué buscaba Cervantes en América latina?», Reforma, 14-01-05.

2. Los libros del conquistador, México, FCE, 1953, p. 236. 
burlescos, tanto en el virreinato del Perú como en el de la Nueva España, donde los plateros hicieron una mascarada grandiosa en el siglo XVII, con motivo de la beatificación de San Isidro labrador, que no puedo dejar de citar por cuanto de literarias tienen sus invenciones: iniciaba la máscara un caballo blanco en cuyas ancas iba la figura de la Fama con vestidura de tela rosada y un tocado del que pendía un velo de plata, alas de variado plumaje y una trompa en los labios, le seguía el labrador con máscara de plata y acompañándolo cuarenta hombres que representaban a:

Todos los caballeros andantes autores de los libros de caballerías, don Belianís de Grecia, Palmerín de Oliva, el caballero del Febo, etc., yendo el último, como más moderno, don Quijote de la Mancha, todos de justillo colorado, con lanzas, rodelas y cascos, en caballos famosos; y en dos camellos Mélia la Encantadora y Urganda la desconocida, y en dos avestruces los Enanos Encantados, Ardián y Bucendo, y últimamente a Sancho Panza, y Doña Dulcinea del Toboso, que a rostros descubiertos, lo representaban dos hombres graciosos, de los más fieros rostros y ridículos trajes que se han visto ${ }^{3}$.

A fines del XVIII, la autoridad de Cervantes es reclamada en la Nueva España por el alcalde Hipólito de Villarreal ${ }^{4}$, quien, en su obra, una suerte de memorial de remedios, lo considera un gran político por el concepto que se formó de las Américas en El celoso extremeño y cita la famosa letanía con la que el ingenio español condenó a las Indias: «refugio y amparo de los desesperados de España, iglesia de los alzados, salvoconducto de los homicidas, cubierta de los jugadores, añagaza general de mujeres libres, engaño común de muchos y remedio particular de pocos». La cita viene al caso por los muchos desocupados que pasan a las Indias, y Villarroel propone que se pase revista a la gente que desembarca en Veracruz y se encierre en el castillo a todo aquel que no venga empleado para que pueda ser regresado en el próximo barco a la península.

\section{Los males de Nueva España}

Coetáneo de este texto, y también sobre los males de la Nueva España, encontramos precisamente a don Quijote y a Sancho, dialogando en las riberas de México, en un largo poema en el que cada uno se cuenta lo que han vivido en

3. Verdadera relación de una máscara, que los Artifices del gremio de la platería de México y devotos del glorioso San Isidro el labrador de Madrid, hicieron en honra de su gloriosa beatificación, compuesta por Juan Rodríguez Abril, platero, México, por Pedro Gutiérrez, en la calle de Tacuba, 1621, citada en Manuel Romero de Terreros, Torneos, mascaradas y fiestas reales en la Nueva España, México, Editorial Cultura, T. G., S. A., 1918, pp. 31-32.

4. Enfermedades políticas que padece la capital de esta Nueva España [1787], México, Gobierno de la Ciudad de México y Miguel Ángel Porrúa, 1999, p. 251. 
su mutua ausencia: don Quijote habla de la España invadida por los franceses, a la que han impuesto costumbres afeminadas. Y Sancho, que lleva cinco años en la Nueva España enrolado como soldado, le describe pormenorizadamente los vicios de la tierra, entre ellos, el lujo de los que vienen de España a ocupar cargos en el virreinato, y sobre todo, el de los hombres, que, al igual que los de España, parecen afeminados, porque imitan a los franceses.

El poema se encuentra en el Manuscrito/12930/24, Poesías varias, de la Biblioteca Nacional de Madrid. Se trata de un cuadernillo de 31 hojas de 20 $\times 15 \mathrm{~cm}$., con letra de fines del XVIII. En el fol. 3v aparece una nota sobre los sonetos introductorios de la que se puede deducir que la copia es de 1790, pero por los hechos que se narran en nuestro poema: las reformas del visitador José de Gálvez, que llegó a la Nueva España en 1765, y la llegada del nuevo virrey a la Nueva España, Antonio María de Bucareli y Ursúa, en 1771, podemos situar su redacción entre esos años, con especial énfasis en el de 1767, año de la expulsión de los jesuitas, que es el acontecimiento más doloroso y más fácilmente evocado por el experimentado Sancho al narrárselo al recién llegado don Quijote.

Esta obra anónima dialogada, una silva de 854 versos, en la que alternan endecasílabos y heptasíbabos, podría calificarse de fantasía satírica y emparentarse con otros textos coloniales, como La endiablada (c. 1624) de Juan Mogrovejo de la Cerda, en la que, a través de un diálogo entre un chapetón y un baquiano, va aflorando la sátira a ciertos tipos y costumbres del virreinato del Perú. En ambas obras, se trata de hechos insólitos: en La endiablada dialogan diablos que tratan de ganar almas y en nuestro poema, dos famosos personajes de ficción de otro siglo, cuya presencia causa mutuo estupor en ambos personajes, porque se saben muertos. De Sancho no se dan mayores datos, ni siquiera llegamos a saber por qué huyó de España, pero él nos cuenta que se fue de «miquelete» a Sonora y que pensaba enriquecerse matando indios, $y$, efectivamente, hacia 1768, el Visitador José de Gálvez «había propuesto que se organizara una expedición militar que habría de dirigirse a la fronteriza provincia de Sonora para combatir allí a los rebeldes seris y pimas que la venían asolando [...] Su mando se encomendó al coronel Domingo Elizondo, militar prestigiado y amigo de Gálvez» ${ }^{5}$, bajo cuyas órdenes seguramente estaría Sancho.

Del propio don Quijote sabemos de su reencarnación en otra persona, cuando se lo cuenta a Sancho, al ver su cara de sorpresa, porque lo creía muerto; su nueva «invención» es haberse convertido en un chapetón que interroga a Sancho, le escucha, y hace acotaciones puntuales de incredulidad o de comparaciones con España. Por parte de ambos personajes hay constantes referencias a la obra que les dio vida y fama: Sancho recuerda al Dr. Pedro Recio de la Ínsula Barataria y los doblones que su amo le dio en Sierra Morena, cuando encontraron a «Cardenio sin calzones»; y don Quijote compara los

5. Ignacio del Río, «Autoritarismo y locura en el noroeste novohispano. Implicaciones políticas del enloquecimiento del visitador general José de Gálvez», Estudios de Historia Novohispana, 22 (2000), pp. 111-138. 
olores de la moda francesa con el Bálsamo de Fierabrás. Sancho se extraña de que don Quijote haya podido huir de la España invadida por franceses, cuando en otros tiempos ningún gigantón lo arredraba y don Quijote le contesta con un discurso de añoranza de una Edad de Oro que ya no existe, porque donde había armas y valor, ahora hay burlas, chanzas y bailes en calles y plazas y los hombres se visten y comportan como mujeres.

Villarroel también se pronuncia en contra de esta moda venida de Francia y piensa que han hecho «más perjuicio los vestidos y hebillas a la Chartre que una inundación, una plaga o un contagio», pero el colmo es que la tropa, al imitar a los franceses en el traje, «se han hecho el espectáculo de la risa con su afeminación, echando a rodar la seriedad española. ¡Infelices tiempos!» ${ }^{6}$.

La nueva «invención» de Sancho es la de un baquiano, cuya experiencia de cinco años le permite no sólo criticar abusos y corrupciones, sino también defender a los súbditos novohispanos como verdaderos sufridores y los mejores vasallos del rey. Los discursos de Sancho con los pormenores de la vida colonial llevan a don Quijote a admirarse de su discreción, al igual que en el capítulo V de la segunda parte de El Quijote, que el mismo traductor tiene por apócrifo por lo bien que se expresa Sancho. En nuestro poema, Sancho es consciente de su papel protagónico de relator de cuentos e interrumpe de vez en cuando su discurso con fórmulas como:

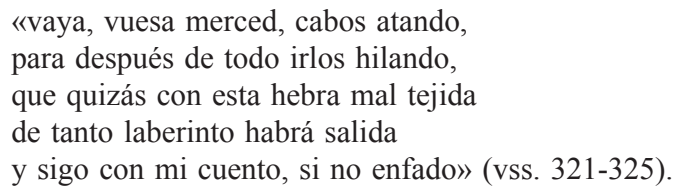

O bien:

«Eche un nudo a ese cabo, y oiga atento, ue malicia hay harta en mi cuento» (vss. 351-352)

cuyo propósito es retardar los hechos y mantener la expectación tanto del lector como de su interlocutor, que, en ocasiones, se desespera y lo conmina a seguir. El Sancho de nuestro poema, como el Sancho de la obra cervantina, es consciente de su caudal como contador de historias y empieza a presentar un mundo al revés en el que al noble se le quita el don, se le dan armas a la plebe, el cochero se burla de su señor y el ejército profana las iglesias.

En el texto salen a relucir otros aspectos de la Nueva España a fines del virreinato, como el lujo de los nobles que llevan carruajes con seis caballos; los cargos en el gobierno siempre para los peninsulares y no para los criollos; se critica la mucha hacienda del rey que se ha gastado; los impuestos al pan, al maíz y a las velas con el pretexto de aumentar el erario público; la limpieza 
de las calles, que antes costaba siete mil pesos y ahora veinte; el encarecido precio del empedrado, y es que al empedrado y enlosado de las calles estaban obligados todos los vecinos y se les daba un plazo de seis meses para hacerlo; todos los propietarios debían contribuir, incluso los conventos que solían pedir exención alegando pobreza.

Sancho desea hablar sin parar de la cantidad de gabelas que se imponen a los habitantes de la Nueva España, como cuando viajó en Clavileño y no parecía terminar nunca de contar a los duques las grandes maravillas que había en el cielo y tuvieron que dejar de preguntarle para que se callara, así don Quijote cumple la función de frenar sus críticas, pues en las páginas finales, Sancho quiere hablar mal incluso de altos cargos religiosos, como el obispo de Puebla, y don Quijote funge como inquisidor y acalla sus quejas. El diálogo es un mano a mano de prohibiciones e invitaciones a hablar. El juego dialógico se asemeja a las prohibiciones que don Quijote le hace a Sancho en la obra cervantina para que no diga más refranes $\mathrm{y}$, al mismo tiempo, le insta para que diga algunos, porque a él no se le ocurren en ese momento. En este texto, el vaivén se da de la misma manera: Sancho habla y critica, y en ocasiones, él solo se autocensura por miedo a la excomunión; don Quijote lo incita a hablar, pero también lo detiene cuando se mete en terrenos peligrosos, sobre todo, en los asuntos religiosos, porque: «Esa materia a Dios es reservada».

Lo más relevante del texto no es precisamente la calidad de sus versos, sino el rescate que se puede hacer como documento de época, sobre todo, por los acontecimientos históricos que relata Sancho al incrédulo Quijote en tiempos de un visitador que hasta muy adentrados en la crítica de los daños que ha hecho, nos dice, al fin, su apellido: Gálvez, a quien califica irónicamente de «ilustrísimo e ilustrado». Se trata de José de Gálvez, Visitador General de la Nueva España entre 1765-1771 y luego Ministro de Indias de 1776-1787, que llevó a cabo una serie de reformas fiscales y económicas, e impuso en cada virreinato «pequeños ejércitos permanentes y de extensas fuerzas milicianas», como en el caso de México, cuyas tropas «reclutadas en el lugar, llegaron a contar con cerca de diez mil hombres, apoyados por regimientos de milicianos de más del doble de tal número» ${ }^{7}$; de ese ejército se queja, precisamente, Sancho a don Quijote a lo largo de varios versos por la cantidad de desmanes que cometen, entre otros, profanar las iglesias y haber sido reclutados sin tener disciplina de soldados. Aparte, la milicia también afectaba los intereses del Ayuntamiento, pues tenía que dotar de bastimento y vestuario a los regimientos $^{8}$. Por ejemplo, el año de 1766, «el procurador general presenta la cuenta del vestuario para los milicianos blancos y pardos» ${ }^{9}$; mucho más grave aún

7. David Brading, Orbe indiano. De la monarquía católica a la república criolla, 1492-1867, México, FCE, 1991, p. 510.

8. M. ${ }^{\text {a }}$ Luisa Pazos y Catalina Pérez Salazar, Guía de las Actas de Cabildo de la Ciudad de México. Siglo XVIII. Años 1761-1770, México, Departamento del Distrito Federal/Universidad Iberoamericana, 1988, p. 19.

9. Pazos y Pérez, 1988, p. 88. 
es que reclutaban a los milicianos entre los diversos gremios, por lo que hay varias protestas en 1766 por la obligada participación gremial.

Otras medidas fiscales que causaron grandes controversias entre los habitantes de la Nueva España. Fueron los portes de la estafeta, el estanco del tabaco, al que dedica varios versos, porque llegó a ser un monopolio real bastante lucrativo, pero, a decir de Sancho, que representa a la voz colectiva del pueblo, al reglamentar su uso, manufactura y venta, dejó a muchos pobres en el reino.

\section{José DE GÁLVEZ Y LA EXPULSIÓN DE LOS JESUITAS}

El hecho histórico más relevante de la obra es, sin duda, la expulsión de los jesuitas, quienes fueron expulsados en tiempos del virrey Marqués de Croix. Carlos III ordenó su expulsión y la incautación de sus bienes. Los padres de la Compañía fueron a despedirse de la virgen de Guadalupe y una multitud llorosa los seguía, acontecimiento del que Sancho deja constancia en nuestro poema.

La vívida descripción de este hecho en la obra está además respaldada por los poemas preliminares que lamentan el terrible decreto, lo cual hace suponer que el ingenio que compuso este diálogo satírico estaba muy emparentado con la Compañía o era uno de sus miembros, porque pone en boca de Sancho la narración de la tragedia con tintes tan dramáticos que incluso admira a don Quijote por el fervor y la vehemencia con que los defiende y hace su apología.

Aunque su autor bien pudo ser también cualquier miembro de la burocracia colonial molesto por la política reformista del Visitador de militarización y mayores impuestos del Visitador, por su favoritismo a que ocuparan los cargos importantes sus compatriotas malagueños y por su nepotismo, ya que impuso a su hermano y a su sobrino como virreyes; de hecho, hubo un anónimo en el que se decía: «Gálvez ha destruido más que ha edificado [...] su mano destructora va a preparar la mayor revolución en el Imperio Americano» ${ }^{10}$, que seguramente fue escrito por un miembro de la elite colonial (jueces, oidores, contadores, fiscales), designado por el virrey Croix como «grupo de la unión y partido antigubernativo», del que también salió un panfleto «favorable a los jesuitas»; ambos hechos coetáneos: Visita y Expulsión no pueden separarse, porque algunos miembros de ese partido «habían atacado la Visita, otros apoyaban a los jesuitas y los demás eran amigos de los desterrados» ${ }^{11}$.

Con su expulsión, Carlos III asestó un duro golpe a la educación y a la cultura. Entre los motivos que se aducen para la expulsión, algunos los

10. Citado por David A. Brading, Mineros y comerciantes en el México borbónico (1763-1810), 2. reimp., México, FCE, 1985, p. 64.

11. Brading, 1985, p. 65. 
condenan por ser los instigadores que levantaron al pueblo en el llamado Motín de Esquilache, pero, según Magnus Mörner ${ }^{12}$, había ya antecedentes de hostilidad contra la orden de Loyola en Portugal con Pombal desde 1759 y en Francia desde 1764. Él alega más bien que pudo haber envidia por parte de otras órdenes religiosas que se dedicaban a la educación, además de que financiera y administrativamente, se llegó a considerar a la orden como una «empresa político-comercial» ${ }^{13}$.

José Vasconcelos, citando a Lucas Alamán, dice, sin embargo, que la expulsión "fue consecuencia de una conspiración de los jansenistas y librepensadores franceses que amedrentaron a Carlos III, exagerando el peligro de supuestas conspiraciones, pero en realidad con el objeto de debilitar el Imperio español que con la ausencia forzada de la orden de Loyola, quedó quebrantado en América» ${ }^{14}$.

Sean cuales fueren las diversas causas que se aducen para la expulsión, lo que interesa destacar aquí es lo que cuenta Sancho sobre los dos eclesiásticos que, en lugar de favorecer al sacerdocio, apoyaron el decreto real de extrañamiento y ocupación de los bienes de la Compañía, estos son, el Arzobispo de México, Francisco Antonio de Lorenzana y Buitrón, y, sobre todo, el Obispo de Puebla, Francisco Fabián y Fuero, que escribió «una magna carta pastoral a favor de la expulsión», porque además de apoyar la decisión real, ya que a Carlos III le debía su nombramiento, también pensaba que los jesuitas habían acumulado riquezas «a fuerza de rapiña al tesoro real» ${ }^{15}$, idea que prevalecía en las Indias, en general.

En el poema se da amplia cuenta de cómo los amotinamientos que hubo por las milicias, así como por los impuestos y los monopolios reales, se llegaron a convertir en una verdadera rebelión cuando se ordenó la detención, confiscación de los bienes y el destierro de los jesuitas; el mismo Gálvez se ocupó de sofocar las rebeliones con los soldados que había impuesto, tal y como se lo cuenta Sancho a don Quijote.

Y es que, junto a los dos prelados, Gálvez fue un acérrimo enemigo de la Compañía, a tal punto que, ante tantas revueltas en varios lugares de la Nueva España, sobre todo, en Guanajuato y San Luis Potosí, llegó a escribirle al virrey Croix que tales rebeliones eran una conjura jesuita y que «si tarda la expulsión de los negros enemigos muy pocos meses más, hubiera perdido la América o para conservarla tendríamos sus vasallos que regar la tierra con mucha sangre» ${ }^{16}$. La expatriación llegó, tal y como era su ferviente deseo, y con ella, la confiscación de sus casas, de sus cinco colegios y de sus iglesias.

12. Magnus Mörner, «Los motivos de la expulsión de los Jesuitas del imperio español», Historia mexicana, 65, XVI, 1 (1966), pp. 1-14.

13. Mörner (1966), p. 4.

14. Breve historia de México, 3. ${ }^{\mathrm{a}}$ ed., México, Fernández Editores, 1986, p. 284.

15. Francisco Rodríguez de Coro, «Francisco Fabián y Fuero, un reformador molinés en Puebla de los Ángeles», Wal-al Hayara. Revista de Estudios de Guadalajara, 17 (1990), p. 187.

16. Brading, 1985, p. 315. 
Tiempos oscuros se narran en este poema, que es, sin duda, un valioso documento histórico que da cuenta de una agitada época de la administración colonial y las reformas borbónicas, bajo el reinado de Carlos III y cuyo promotor fue el Visitador José de Gálvez. El juego dialógico cobra mayor fuerza por estar puesto en boca de los dos personajes más importantes de la literatura universal, aunque sus funciones sean distintas: el valiente manchego es un timorato bisoño que trata de restar importancia a la realidad con un espíritu conservador y Sancho, en cambio, es el intrépido denunciante que aboga por la justicia, clama por el abuso de impuestos y delata los males del mal gobierno no de su Ínsula Barataria sino del virreinato de la Nueva España a unas décadas de su Independencia.

\section{EDICIÓN DE ESTE TEXTO}

Se ha puntuado, modernizado y acentuado el texto. Añado entre corchetes las letras que faltan y suprimo entre paréntesis las que sobran. He eliminado para esta edición los poemas preliminares que versan en torno a la expulsión de los Jesuitas y abarcan desde el fol. 1v hasta el 12r, donde empieza realmente nuestro diálogo.

Siglas utilizadas:

DRAE: Diccionario de la Real Academia Española.

Tesoro: $\quad$ Sebastián de Covarrubias Horozco, Tesoro de la lengua castellana o española.

MM: $\quad$ María Moliner, Diccionario de uso del español. [fol. 12r]

«Oportuno encuentro del valiente manchego don Quijote con su escudero Sancho Panza en las riberas de México. Obra póstuma de los dos, e instrucción de la presente historia. Guardada del público para su duración, un apasionado del asunto».

\section{Don Quijote-Sancho}

DON QUIJOTE ¿A dónde bueno, Sancho amigo?

SANCHO El nombre de Jesús esté conmigo.

DON QUIJOTE ¿Qué extremo es éste?, ¿te has quedado yerto?

SANCHO Por fuerza lo he de estar, si me habla un muerto.

DON QUIJOTE No creas esto, si el cuerpo morir pudo, 5

no pudo aqueste espíritu hazañudo,

ni aún mi juicio, según el tiempo abona ${ }^{17}$,

17. Abonar: «acreditar o calificar de bueno». (DRAE) 


\section{SANCHO DON QUIJOTE \\ SANCHO DON QUIJOTE SANCHO}

DON QUIJOTE

SANCHO

DON QUIJOTE

SANCHO

DON QUIJOTE

SANCHO

DON QUIJOTE

SANCHO

DON QUIJOTE

SANCHO
Porque se ha trasferido a otra persona; $\mathrm{y}$, aunque con invención ${ }^{18}$ bien diferente, me tendrá en ella el mundo muy presente.

Luego, ¿vuestra merced es de este mundo?

Sí lo soy, mas de verte me confundo en tierra tan distante y tan extraña. [fol 12v] Vine huyendo de España. ¿Por qué de España has huido?

Es largo de contar ¿Por qué ha venido, su merced, a esta tierra?

Porque hoy, allá, el más atento yerra, y con estar mandando malandrines

- los que son para España gachupines - ${ }^{19}$ poner quise distancia de por medio, y vine a acá buscando mi remedio.

Pues iguales estamos ¿Cuándo ha sido esa buena venida?

Poco ha ha sido.

Habrá que vine yo como cinco años.

Luego, ¿ignoras de España tantos daños?

Si por daños lo habemos,

mil veces más que allá, acá tenemos.

Pues, dime los de acá, que ya te escucho.

Dígame los de allá, porque esto es mucho.

De todos hablaremos,

allá no se habla.

Ni acá, pero hablemos:

¿Es posible, señor, que el brazo fuerte

de su merced se halle de esta suerte? [fol. 13r]

¿de unos franceses ahora huya,

sin acordarse de la fama suya,

cuando a los gigantones de dos voces

postraba?

DON QUIJOTE Ya no valen los Quijotes

en España, que es todo una mudanza;

la espada no se usa ni la lanza;

el bigote se tiene abandonado, y como en ironía, se dio al soldado, la barba ya envilece; y el que no está afeitado, no parece en público, a ser sólo sindicado 
SANCHO

DON QUIJOTE

SANCHO

DON QUIJOTE

SANCHO

DON QUIJOTE

SANCHO

DON QUIJOTE

SANCHO

DON QUIJOTE

SANCHO y en andar a compás siempre bailando, por calles y por plazas silbando.

¿Y sabe, su merced, en qué está esto?

En que el viento trastorna el poco seso.

Ya traen encajes, borla, redecilla, el zapato alustrad[o] con la hebilla; ancho el calzón, de tafetán y seda, por ser mujer cada uno en cuanto pueda; [fol. 13v] ya usan catres cubiertos en campaña, porque la tez el aire les empaña; traen licores y bálsamo oloroso —no del de Fierabrás, tan provechosoy otras cosas que, si decir pudiera, con ser verdad, quizá, no se creyera, mas, si vieras lo que es allá el cortejo, sí creyeras; por eso, yo me alejo, y este enfado de España me retira. Pues, señor, esto mismo acá se mira. Paciencia, Sancho bueno, y tolerancia, porque estas son las flotas de la Francia. Y ¿por qué estás desnudo y macilento, tan pobre, tan enfermo y tan hambriento?

Luego, ¿vuestra merced también ignora que fui de miquelete ${ }^{21}$ a la Sonora?

Sí lo ignoro, y, suspenso, no imagino cuándo y por qué tomaste tal destino. Cuando un señor, de autoridad no vista, liberal, nos convida a una conquista, donde cualquier zoquete, con un brinco, indios podía matar, de cinco en cinco, $\mathrm{y}$, haciendo en sus pellejos bolsas tales, [fol. 14r] traer oro y plata, a cargas y a costales.

Si en sólo matar indios consistiera tener mucho dinero, ya no hubiera en el reino pobres, pero necio fuiste, pues con tal ligereza, así lo creíste. ¿No te hacías cargo, carnicero lobo, que el conquistar por plata sólo es robo?

Esos puntos, por necio, no me tocan, y más cuando otras grandes ${ }^{22}$ me provocan a admitir un empleo tan absoluto de honra y provecho.

¿En qué consiste, bruto?

En que los miqueletes, a su entrada, profesaban no hacer, de bueno, nada, y en libertad que dieron de conciencia, 
malo fue cuanto hicieron de experiencia: las mujeres, los juegos, las bebidas pagaban con bravatas ${ }^{23}$, con heridas, $\mathrm{y}$, aunque a vista de todos, se paseaban, los jueces sus excesos toleraban; y esta amplitud me persig[u]ió en tentarme, y quise, como tantos, calentarme; no quedó pícaro de marca entera ${ }^{24}$ [fol. $\left.14 \mathrm{v}\right]$ a quien en tal facción no se admitiera; $\mathrm{y}$ aun parece, según se vio patente, que de estos se buscaban solamente.

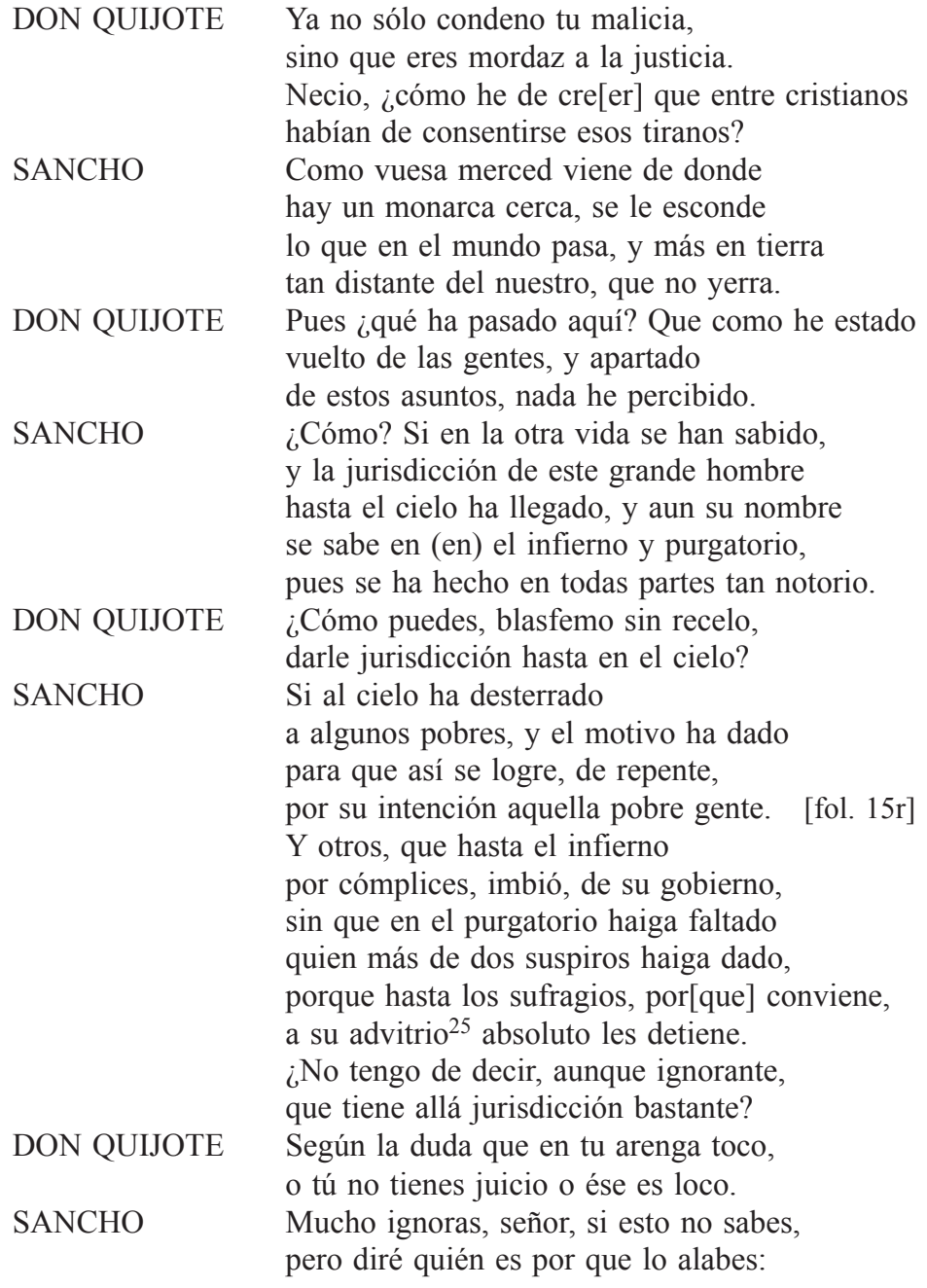

\section{DON QUIJOTE} Ya no sólo condeno tu malicia,

23. Bravata: «amenaza proferida con arrogancia para intimidar a alguno». (DRAE)

24. De marca entera: «de marca mayor, o sea, que sobrepuja a lo común». (DRAE)

25. Advitrio: arbitrio, voluntad, autoridad, poder. 
DON QUIJOTE

SANCHO DON QUIJOTE

SANCHO

DON QUIJOTE SANCHO

DON QUIJOTE

SANCHO

DON QUIJOTE

SANCHO éste es un licenciado, que en la Corte, creo que abogado fue de medio porte, para visitador disque fue enviado, aunque, hasta ahora, a nadie ha visitado, pues con advitrios ${ }^{26}$ solo ha movido cuanto hay de polo a polo, que es ahijado, y discípulo en substancia, embajador, teniente del de Francia.

Después que acá ha llegado, ilustrísimo ha sido e ilustrado, pues que de todo sabe y en su cabeza todo el mundo cabe.

o no me puedo persuadir a eso oyendo tantos disparates juntos.

Pues aún faltan a vuestra merced otros asuntos.

Di, Sancho hijo, por que acabe en breve

de cre[e]rte o de que el diablo antes te lleve; ¿ese visitador de dónde vino?

Porque, a lo que me dices, imagino que algún follón encantador es ese enemigo encubierto, y que aparece con pretina y golilla, pues con maña quitarle quiere tanta gloria a España. Pues de España ha venido muy pagado a aumentar el erario.

¿Y lo ha aumentado?

No sé yo, mas, si oímos a la gente, que lo ha destruido dicen comúnmente.

No creas tú que el rey sepa lo que él hace o el espíritu al menos de que nace.

Yo en eso no me meto, ni Dios quiera que me meta en materia de esa esfera. ¿Qué no ha habido hombres cultos que escriban a Madrid estos insultos?

Si como de esos hubiera, si como de antes la estafeta fuera, pero desde el principio, como quien para una obra (ilegible) [fol. 16r] en administración (tachado) el rey pone la conducción de cartas y dispone se pague por su peso sin excepción su porte, y con todo eso más que lo que ha de darle el beneficio.

DON QUIJOTE No fuera óbice ése si importara.

26. Advitrios: impuestos municipales para gastos públicos. 
SANCHO Otra providencia hubo que es más cara

en que a los más valientes han temblado

las corazas, y todos han callado

que el que ha escrito con celo y aun con maña

ha ido a seguir sus méritos a España ${ }^{27}$.

DON QUIJOTE Cosas me dices que a no creer me inclino.

SANCHO

Lo mismo contará cualquier vecino,

pues tan notorio ha sido ese gran miedo, que todo hombre mortal se ha estado quedo.

DON QUIJOTE ¿Qué no ha habido virrey que vea este exceso?

SANCHO

Si lo ha habido, la gracia ha estado en eso, que siendo el virrey bueno, y muy humano

ha sacado las brasas con su mano, como allá en mi gobierno hacía conmigo

el Doctor Pedro Recio, este su amigo ha hecho con el virrey, y está muy ancho [fol. 16v] en que el virrey también le fue un buen Sancho. 200

DON QUIJOTE Déjame, Sancho, no me vuelvas loco.

SANCHO DON QUIJOTE ¿Ve, Vuestra Merced, cuanto le he dicho? Pues es poco. De varios en Madrid aseguraron que se desaparecieron porque hablaron, pero enviarlos allá, a donde entiendo que hablen con más efecto, no comprendo.

SANCHO Lo que a mí me hace fuerza sólo ha sido la tolerancia humilde que ha tenido tanta gente de honor, tanto hombre fuerte.

DON QUIJOTE La lealtad no procede de otra suerte.

Dichosos son los pueblos que con tales vasallos, siempre amantes, siempre leales a su rey, a el estado, a su obediencia sufren, y esperan otra providencia; que el oficio de Rey es el más grave, y no siempre estas cosas el rey sabe. El vasallo obediente al rey dispensa mientras se instruye y el remedio piensa, pues suponer debemos que los reyes, por hacerlo mejor, hicieron leyes.

27. Entre algunas personas hostigadas y varios de ellos exiliados en España cabe destacar a «Pedro de Rada y Martín de Aspiroz, de la Secretaría del Virreinato; al fiscal de la Real Audiencia, Juan Antonio Velarde; al oidor Francisco Javier Gamboa; al decano del Tribunal de Cuentas, Alonso de Mella y Ulloa; al contador general del Ramo de Tributos, José Rafael Rodríguez Gallardo, que había sido visitador y gobernador interino de Sonora y Sinaloa, y al alcalde de corte Diego Fernández de Lamadrid. A esta nómina habría que agregar a varios clérigos, como Francisco López Portillo, Antonio Lorenzo López Portillo, Ignacio Ceballos e Ignacio Javier Esnaurriza. La remisión de ocho de estos personajes a España el año de 1769 libró a la administración virreinal, según palabras del historiador Luis Navarro García, de otros tantos "espíritus inquietos... opuestos a las directrices de la visita general y de la política llevada por Carlos III”» (Ignacio del Río, 2000, p. 115). 
SANCHO

\section{DON QUIJOTE}

SANCHO
Quien siempre obedece con afecto, su intención obedece, no el efecto, que en su mano no está más vigilancia, [fol. 17r] ni el verlo todo, y más en tal distancia.

$\mathrm{Su}$ Merced no se empeñe en tanto exceso que de lealtad es esta tierra aborto, y si supiera el rey cuanto ha pasado, y por su amor sufrido y tolerado tuviera a estos vasallos, bien lo fundo, por más leales que a todos los del mundo.

Calla, Sancho, que tu pasión te engaña ¿no sabes la lealtad que hay en España? Mucha hay, pero es mayor aquesta, y vea, vuesa merced, si lo pruebo en mi respuesta. ¿Hay nación en el mundo a quien suceda lo que a ésta, que no pueda emplear su advitrio, su trabajo o mañas que todo es contrabando para España? ¿Y, aunque en tierra tan fértil Dios lo cría, las muchas provisiones los desvía de coger el maná que acá les llueve, pues a agraviar a España no se atreve? Aquí no hay tropas, viñas ni telares en que ocupar los hombres a millares, ni hay advitrio, ocupación ni oficio que de España no venga con perjuicio aun en su honor, que muchos les arguyen [fol. 17v] de inútiles y ociosos, y atribuyen defecto personal en conseguirlo, y aún Mitra $^{28}$ hay que se atrevió a decirlo por conseguir, por medio desusado, el injusto acomodo de algún criado.

Los países se han servido de los que allí han nacido, pero los que aquí nacen,

a estar ociosos por destino se hacen.

¡Ella fuera gran vida,

si de España trajeran la comida a estos pobres indianos, o les dieran virtud de no comer, qué buenos fueran!

$\mathrm{Y}$ con todo, sintiendo tanto agravio, a ninguno se ve que asome el labio, porque el silencio a su lealtad le deja por puro sacrificio de su queja.

A esta llamo lealtad, que en este modo, viva obediente, y que lo sufra todo; no tanto la de España, que en su vida se vio más abundante ni aplaudida. 
DON QUIJOTE Que eres discreto, Sancho, ya imagino, nunca en casa pasaste de pollino.

SANCHO Es virtud de la mar, y ya he pensado que eso consiste en sólo haber pasado. [fol. 18r]

DON QUIJOTE SANCHO Dime, en fin, lo demás, que ya te escucho. Nunca podré decirlo, porque es mucho, y a empezar me acomodo, de tal modo que mucho sepa sin contarlo todo: cuando menos pensaba el reino todo, porque en paz estaba, una tropa crecida y misteriosa vino de España a no servir de cosa. Seguro su proyecto considera - y no lo estaba, si lealtad no hubiera-, cercaron la ciudad, esto es, de adentro; y empezó la compañía por el centro viéndose en su concepto asegurados, tropas intentan crear de más soldados.

DON QUIJOTE Lo contrario se infiere, que aún temían, pues más soldados levantar querían.

SANCHO No tal, que en el propio hecho dispusieron el asalto primero que les dieron no en hacerlos soldados, que esta gente es esforzada, es útil, y es valiente sino en el modo con que los llamaban, pues el don hasta al noble le quitaban; y en público, después, con ignominia, la medida de todos, vil insignia [fol. 18v] fue una propia medida a todos ellos, blancos y prietos, nobles y plebeyos, ricos y pobres, amos y criados, oficiales ociosos, y aun empleados, y con este desorden e impericia, varios cuerpos ordenan de milicia, con desprecio formal de lo obediente, haciendo burla de ellos propiamente. Dejo aquí muchas quejas y paso a las reflejas ${ }^{29}$ de que siendo este reino perseguido de la plebe, a quien siempre le han temido, a la plebe ensalzaron y le dieron de armas la posesión que no tuvieron y el militar desahogo y disciplina de soldados, que aquesta es su doctrina, con que el cochero al amo sonrojaba, y si tenía rencores, los vengaba.

29. Refleja: «conocimiento o consideración que se forma de una cosa para reconocerla mejor». (DRAE) 
DON QUIJOTE SANCHO DON QUIJOTE

SANCHO

DON QUIJOTE SANCHO

DON QUIJOTE

SANCHO

DON QUIJOTE

SANCHO
Que estás apasionado, Sancho, siento.

Todo ha sido notorio, en nada miento.

Pues, hombre del demonio, ¿qué provecho, al fin, sacaban de tan torpe hecho?

Eso tiene un misterio que no toco, [fol. 19r]

No pienso en él por no volverme loco;

vaya, vuesa merced, cabos atando, para después de todo irlos hilando, que quizás con esta hebra mal tejida de tanto laberinto habrá salida y sigo con mi cuento, si no enfado.

Antes fue admiración, y ya es cuidado.

Pues callo de la tropa los excesos, porque estos fueron siempre sus progresos; no digo los castigos, pues son llanos, nunca en la tropa, siempre en los paisanos, y omito otras mil cosas; sólo digo que vimos, y cada uno fue testigo, la iglesia, sin respeto, atropellada. Dígalo Santa Cruz tan vulnerada, que dentro de la Iglesia - igrande arrojo!mataron tres o cuatro por su antojo, de los que allí se hallaban convecinos oyendo una misión de fernandinos ${ }^{30}$; y el jefe de esta tropa, rostrituerto, estimó por victoria el desacierto, mostrando en lo inflexible e inhumano ser en Ceuta más moro que cristiano. [fol. 19v] Gran desacato fue ese, Sancho amigo, ¿no quedaría la tropa sin castigo?

Si los heridos no escaparon luego, se hubieran castigado a sangre y fuego; pero los agresores desatentos quedaron lisonjeados y contentos.

Sigue adelante, Sancho, que ya inicia tanto error en mi juicio otra malicia.

Eche un nudo a ese cabo, y oiga atento, que malicia hay harta en mi cuento.

Ya en este tiempo, había

aquel visitador de nombradía

ido con sus secuaces

desbaratando paces

en todo el reino entero,

alterando las rentas y, severo, 
quitando arrendadores,

poniendo por el Rey otros factores ${ }^{31}$,

con cuyo hecho, de hecho, y sin porfía, un catorce por ciento se perdía, añadiendo aflicción, y fuerza extraña a los vecinos de la Nueva España, [fol. 20r] pues con nombre del Rey les exigían

doblados los derechos que debían y las rentas que enteras se pagaban ya sin aquel catorce se contaban.

A esto llamaba aumento del erario, y era sólo un destrozo voluntario.

En ese tiempo se estancó el tabaco dando a los pobres un perenne $\operatorname{saco}^{32}$, y aunque sólo esta renta es provechosa, como fue a sangre y fuego, se hizo odiosa, y la puso, aun pendiendo ${ }^{33}$ de su mano,

contra la voluntad del soberano, pues prestó su licencia (al fin, es padre) con condición que a sus vasallos cuadre. ¡Qué lástimas, qué penas, qué lamentos publicaban los pobres a los vientos! porque era este comercio el socorrido donde todo infeliz tenía partido, y, estancado el tabaco así y sus usos, en todo el reino corren sus abusos.

DON QUIJOTE ¿Y esos pecados son de entendimiento o de voluntad? [fol. 20v]

SANCHO Nunca es mi intento denigrar a ninguno, ni esto digo, más que por instrucción de un fiel testigo, porque yo, indiferente soy y he de ser en todo lo que cuente, que en diciendo desnudo todo el hecho, ponerlo, su merced, sabrá en derecho, pero sólo me choca por mi cuenta que el fin es aumentar y no se aumenta.

DON QUIJOTE Eso lo dirá el tiempo, y el engaño se advertirá en uno lo de otro año.

SANCHO ¡Cómo de esos pasaron y han corrido y de nada de lo errado se ha advertido!

DON QUIJOTE Pues ¿qué piensas tú en esto, majadero? SANCHO Yo pienso poco, y malo, y con agüero.

31. Factor: «oficial real que en las Indias recaudaba las rentas y rendía los tributos en especie pertenecientes a la Corona». (DRAE)

32. Saco: saqueo.

33. Pendiendo: dependiendo. 
DON QUIJOTE ¿Qué agüero puede haber en lo que toco?

pues el mayor que pienso es que esté loco.

SANCHO Mayor me lo he pensado, vaya oyendo, que Dios a mí me entiende, y yo me entiendo.

DON QUIJOTE Siempre has sido ligero y misterioso,

consecuencias de un genio malicioso.

SANCHO Si cuanto en este asunto he maliciado [fol. $21 \mathrm{r}$ ] me ha salido verdad, ¿en qué habré errado?

DON QUIJOTE En creer lo peor.

SANCHO Lo peor nunca he creído, sólo entre tanto malo lo he temido.

DON QUIJOTE

SANCHO

Cosas grandes del mundo se contaron.

Por eso grandes males se lloraron.

DON QUIJOTE

SANCHO

En fin, ¿no hay más hasta ahora que todo eso?

Tanto más hay, que pienso que ahora empiezo, $y$, aunque el dolor aflija mi memoria,

DON QUIJOTE por lamentable, seguiré mi historia.

SANCHO

Pues acaba ya, di.

Ay, que no puedo, que de sólo apuntarla, tengo miedo.

DON QUIJOTE Empieza ya, que en tu fingida calma, pendiente de su extremo tengo el alma.

SANCHO Multiplicados, pues, tantos soldados y en número crecido amontonados, sin distinción, entre ellos, los cocheros, los sastres, albañiles, zapateros, zurradores ${ }^{34}$, herreros, cargadores, de todas castas, mañas y colores, en los paseos, milicias, y arreglados, que esta la tropa fue de levantados, [fol. 21v] con el comercio, todos numeraban más de cinco o seis mil, los que contaban.

El día del Corpus ipensamientos viles! por que amaguen seis mil o más fusiles, marchar a todos juntos se previno, siendo el primer alarde ${ }^{35}$ a lo divino. ¡Oh, banderas benditas! ¿que éstas sean las que contra la iglesia así se emplean? por que, junta la tropa, temor diera y en su defensa, el pueblo se abstuviera: este sagrado día fue el amago y el de su octava ${ }^{36}$ sucedió el estrago, haciendo más extraña y menos vista la desgracia en la noche del Baptista, que aun los turcos celebran y los moros

34. Zurrador: «el que quita el pelo a las pieles y las curte». (MM)

35. Alarde: exhibición militar de armas y soldados.

36. La octava de Corpus. 
con festivos obsequios, no con lloros, porque, al siguiente día,

cercada amaneció la Compañía, sus casas cuatro, y calles inmediatas pobladas de armas, órdenes, bravatas, y aun toda la Ciudad de prevenciones, patrullas, providencias, invenciones, y lo que más al Cristianismo abisma [fol. 22r] fue el ver las armas en la Iglesia misma, al divino señor sacramentado, hasta entonces en ella adorado, mandan que se consuma; acción prudente por que el Comisionado no lo intente. Presos así, en sus casas, y arrestados los Jesuitas, suspensos y embargados, más bien que de sus bienes, de sentidos, pues, aunque en caridad todos unidos, el golpe tan violento, y no esperado alteró por lo menos lo animado; pero luciendo entonces su instituto, en su obediencia pagaron su tributo.

Fue igual el asalto y tropelía en colegios y haciendas que tenía en todos estos reinos y obispados esta familia, a fuerza de soldados.

Cuál fuese el sentimiento nadie ignora pues toda la Ciudad con razón llora, suspira, se deshace, y en sólo su dolor se satisface, pintarlo no es mi intento, [fol. 22v] pues dejo a la refleja el sentimiento. Lo que adentro pasó se hizo notorio porque hallaron cocina y refectorio, con una provisión muy ordinaria, prueba de su pobreza voluntaria, pues la bodega de la sacristía lo más curioso y rico contenía —dándole lo mejor a lo divino que honra y gloria de Dios fue su destino-, cilicios, penitencias a millares, no secretos antojos de vulgares. En fin, el día tercero,

con la humildad cada uno de un cordero, alegres los semblantes, sus ánimos serenos y constantes, dando con su paciencia un testimonio fiel de su conciencia, salieron desterrados al arbitrio de guardas y soldados. 


\section{DON QUIJOTE}

SANCHO
El cómo quedó México afligido, temeroso, asustado, sumergido al dolor, a la pena, al sentimiento, [fol. 23r] 495 no lo puedo decir ni tal intento.

Pues ¿qué al advitrio estuvo del soldado el vulnerar la iglesia y lo sagrado?

¿No hubo quien defendiera sus respetos tan altos?

Bien pudiera,

mas pienso que prestaron su obediencia a la expulsión, y a toda la violencia.

El Arzobispo, ilustre mexicano, y el obispo de Puebla ${ }^{37}$, que es su hermano, ambos se conformaron sin desvelo,

que ya apóstoles no hay, sino en el cielo.

Bien lo lamenta el sacerdocio santo, que nunca se ha mirado en tal quebranto, agraviado, ultrajado y abatido, como en esta ocasión, y perseguido.

DON QUIJOTE Válgame Dios, suspenso al oírte me he quedado, y sólo pienso que providencia tal nunca se diera si el delito probado no estuviera.

SANCHO ¿Qué delito, señor, pues qué ha creído que culpa los Jesuitas han tenido? [fol. 23v]

DON QUIJOTE ¿No son hombres? ¿Pues qué milagro fuera haber dado mil causas?

SANCHO No pudieran, que aquí ciernen y escogen solamente al que es santo, al que es docto y obediente.

Pues, ¿cómo aquesto, dime, en razón cabe?

En eso no me meto, el Rey lo sabe y pues que lo mandó, me he persuadido que motivos muy graves ha tenido; no inculco yo la causa, si defiendo que inocentes están, y así lo entiendo.

Bien pudo allá en justicia y estar en quien le informa, la malicia, pues ser justo el mandato no concluye el ser justa la causa que se arguye.

DON QUIJOTE SANCHO ¡Discreto estás, increíble es lo que escucho! Estos casos, señor, enseñan mucho.

DON QUIJOTE

SANCHO
Y, dime, ¿a esos jesuitas que lamentas, tanto debes, para que así los sientas?

No sólo siento yo, lo sienten todos, 
es general su falta en muchos modos, porque eran en la corte [fol. 24r] de los que la navegan, fijo norte: al pobre socorrían, al rico, en sus aciertos, dirigían, 540 enfermos consolaban, ignorantes y niños enseñaban. Predicaban constantes, en cárceles y calles, vigilantes, confesaban piadosos, ricos, pobres, vestidos y andrajosos, y por decirlo todo en un minuto, de todo se formaba su instituto.

En lo predicador eran Guzmanes ${ }^{38}$, a pesar de mastines y otros canes; en lo observantes, franciscanos fueron, pues su pobreza y humildad tuvieron; por ermitaños, eran augustinos y hospitalarios como los juaninos ${ }^{39}$; mercenarios parecen, redentores, ¡oh, cuántos redimieron, pecadores! Fueron camilos ${ }^{40}$ por agonizantes, y camilos quedaron como antes, carmelitas en sí contemplativos [fol. 24v] y hipólitos ${ }^{41}$, al fin, caritativos; que si el Patriarca suyo tomó tantos ejemplos para serlo como santos, por consecuencia clara bien concluyo que muchos institutos juntó al suyo; vea, vuesa merced, si con razón el mundo siente la falta universal y trascendente, pues no para en su falta este perjuicio,

DON QUIJOTE SANCHO que para otros mayores es indicio. ¿Mayor perjuicio aún tu temor espera? Mayor pudiera ser, Dios no lo quiera, pues que toda la iglesia es perseguida, $\mathrm{y}$, por distintos modos, afligida.

DON QUIJOTE Habla sin desconfianza, hombre del diablo. SANCHO En materias futuras, nunca hablo, y ni aún de lo presente hablar intento, sólo de lo pasado es lo que cuento.

DON QUIJOTE Pues, di, de lo pasado ¿qué has pensado?

38. Guzmanes: de la orden dominicana, fundada por Santo Domingo de Guzmán.

39. Juaninos: de la orden hospitalaria de San Juan de Dios, fundada en Granada en el siglo XVI y que llegó a México desde 1604.

40. Camilos: pertenecientes a la congregación fundada en Roma por San Camilo de Lelis para el servicio de los enfermos.

41. Hipólitos: orden de los hermanos de la caridad de San Hipólito, que fundaron el primer hospital de la Nueva España para enfermos mentales, en 1566. 
SANCHO Me explicaré en un símil figurado:

si tuviera almacenes abundantes

$\mathrm{y}$ en ellos unos perros vigilantes

que la casa guardaran de ladrones [fol. 25r]

¿qué hiciera, si advirtiera, en ocasiones,

que a estos perros veneno les echaban

y a quitarlos de en medio así anhelaban?

DON QUIJOTE Basta, Sancho, que ya tu frase entiendo.

SANCHO Cuidado con la casa, esto encomiendo.

DON QUIJOTE Tanto miedo en hablar es cobardía.

SANCHO

No quiero ser ahorcado todavía.

DON QUIJOTE

¿Pues por hablar no más se ahorca a ninguno,

no se ha de dispensar alivio alguno?

SANCHO No, señor, que por bando ha sancionado

en aquel propio día publicado;

se hizo callar a todos con gran ruido

que para eso vasallos han nacido.

DON QUIJOTE No han nacido vasallos en mi juicio

los que callan al rey tanto perjuicio;

¿y tuvo efecto el bando promulgado?

SANCHO Muchas vidas costó el haber hablado.

DON QUIJOTE ¿Cómo así? Pues ¿qué hablaron o dijeron?

SANCHO Por sospechosa la prisión tuvieron,

y viendo sin razón ni antecedentes

soldados en la iglesia de repente

—que bastaba un decreto a obedecerlo [fol. 25v]

pues el rey es quien es y puede hacerlo-

como gente sencilla y sin cultura,

en su juicio su celo se asegura,

que las armas y acciones de aquel día

era[n] posesión de la herejía;

por esto se inquietaron,

$\mathrm{y}$, asustados, corrieron y lloraron

por calles y por plazas,

dejando de dolor hasta sus casas

por seguir a la iglesia

que, sobre todo, aquella gente aprecia

y estimando estas señas por tumulto

el señor Gálvez ${ }^{42}$ castigó el insulto

con muertes a docenas,

con azotes, presidios y otras penas,

con venderles sus tierras y sembrados

sin justificación de ser culpados.

42. Se refiere a don José de Gálvez, Visitador enviado por la Corona a la Nueva España «con tales facultades extraordinarias que puede afirmarse que él desempeñó el virreinato de 1765 a 1771 , efectuando una profunda reorganización administrativa en todos los órdenes, especialmente en el económico» (José Ignacio Rubio Mañé, El Virreinato, 4 tomos, México, UNAM/FCE, 1983, T. I, p. 89). 
DON QUIJOTE

SANCHO
SANCHO

Como cierto se supo que habían muerto si no inocentes, por delito incierto; esa tierra dentro desdichada, por esto y otras cosas destrozada.

[fol. 26r]

Y eso, como lo dices ¿lo ha sabido 625 nuestro Rey y Señor?

Tal no he creído, antes pienso que todo mal pintado $\mathrm{y}$ al temple de su antojo figurado con mapas de la moda a la francesa a nadie más se oculta la certeza, que en pecho tan piadoso y tan cristiano menos que todo, cabe lo inhumano.

DON QUIJOTE No sufre más mi antigua fantasía ni tanto cupo en ella con ser mía ni hubo en el mundo caballero andante que acometa a aventura semejante. Y, dime, ¿ese andante caballero se sirve solo o tiene su escudero? Tiene varios, y todos son tratados por caballeros nobles, no por criados.

Por un Machado ${ }^{43}$ empieza, que dicen que, en secreto, es grande pieza; secretario no más había sonado y hoy hasta el virreinato se ha internado.

Él lleva las alforjas y confianzas 645 no montando en pollino, en esperanzas, [fol. 26v] con soberbia tan vana y tal desbroche, (sic) que seis caballos tiran de su coche. Sabe tachar decretos con audacia y sabe hacer justicia con gran gracia. Un Valera ${ }^{44}$ con nombre de abogado - que así lo aseguraba un licenciadosemi-visitador queda en su audiencia desempeñando el hueco y su conciencia; y tantos se contaban entre los que vinieron y acá estaban que individuarlos muy difícil era si como no es del caso, acaso fuera. ¡oh, qué de renegados contar puedo! Unos por interés, otros por miedo, unos, del rey temiendo los enojos, cierran, como Pilatos, los dos ojos; $\mathrm{y}$ otros viles pretenden calentarse al fuego en que a otros miran abrasarse.

43. Machado: Francisco Javier Machado vino como secretario general de la visita y pasó a serlo también del virreinato, en sustitución de Pedro de Rada (Ignacio del Río, 2000, p. 116).

44. Valera: Juan Antonio Valera, otro de los hombres de confianza del Visitador. 
DON QUIJOTE De ese defecto están los pueblos llenos,

si no pueden ser malos, se hacen buenos, $\mathrm{y}$, en sintiendo ocasión, sin intervalos, lo bueno desean, se declaran malos, pero aún mis dudas duran y mi refleja apuran.

¿qué interés han tenido todos esos en tantas tiranías, tantos excesos?

SANCHO No sé yo el interés que hayan tenido, más noble que el dinero es el que ha habido, pues plata y oro no les ha llevado, que en nada de esto se han interesado, a excepción de los nobles escuderos, que para ellos se hicieron los dineros, según la ley de caballero andante, como en Sierra Morena, que, observante,

me dio vuesa merced ciertos doblones aun hallando a Cardenio sin calzones. El principal no ha delinquido en esto aun siendo el de aumentar común pretexto, y pretexto le llama, por sabido, que en lugar de aumentar ha disminuido.

Otro interés pudiera, mas, prudente, no lo quiero decir, lengua, detente.

DON QUIJOTE ¿Qué detención es esa misteriosa? hombre del diablo, ¿sabes otra cosa? [fol. 27v] 690

SANCHO Yo no sé más que lo que ya he contado, que en proyectos sin frutos se ha gastado mucha hacienda del rey, que estos proyectos al principio avisaron sus efectos, que a la Ciudad precisa a gastos tales, que ni rentas le deja ni caudales, porque en tropas, cuarteles y vestuarios consumieron los propios ${ }^{45}$ necesarios, que las limpias de calles que costaban como siete mil pesos, hoy pasaban de veinte muy cumplidos, manteniendo haraganes conocidos con este pan, que fue de pobres antes dándolo a perros hoy, extravagantes, $\mathrm{y}$ sin dejar arbitrio conveniente para la juventud más inocente, que cuando más se esmeran con gabelas ${ }^{46}$ en el pan, en el maíz y aun en las velas

45. Propios: «heredad, dehesa, casa u otro cualquier género de hacienda que tiene una ciudad, villa o lugar para satisfacer los gastos públicos». (DRAE)

46. Gabelas: «tributo, impuesto o contribución que se paga al Estado». (DRAE) 
DON QUIJOTE
SANCHO

SANCHO

DON QUIJOTE

SANCHO pretextando aumentar el Real erario, no se advierte el consumo voluntario 710 en la que vino al reino, tropa ociosa, a conquistar virtudes, no otra cosa, [fol. 28r] ni a los gastos crecidos y excusados de Alamedas ${ }^{47}$, garitas ${ }^{48}$ y empedrados. Ni sé otra cosa que pensar, prudente, que hacer pobres a todos hoy se intente, gastando por gastar sin más provecho que no hayga más que hacer porque ya está hecho. No entiendo, Sancho, tu frasismo errado. Ni yo por que se entienda lo he contado, que mi ánimo no era dar razón tan entera como he dado.

DON QUIJOTE Con todo, no he entendido la sustancia del cuento, sólo el ruido, y mil dudas me pulsan, pues no infiero

el fin de tanto yerro.

Lo primero que yo sólo ofrecí contar el cuento y no estoy obligado a su comento.

Lo segundo, que su merced es un diablo y que entiende muy bien cuanto yo hablo.

¿Qué empedrados son esos que has contado? que también en Madrid hubo empedrado. [fol. 28v]

El virrey, que de casa no salía ni las calles de México sabía, precisó a los vecinos y conventos

a que empiedren según sus pensamientos.

Estos fueron costando cada vara lo que antes media calle no costaba, consumiéndose en tales producciones

a cuenta de las fincas tres millones;

y aunque se le hizo ver su desatino y el destrozo común se le previno no cedió en su proyecto aconsejado y se empezó a este costo el empedrado.

DON QUIJOTE En Madrid se gastaron muchos miles en estas obras y otras más serviles.

SANCHO
Acá se dieron providencias varias para esto de imponer las necesarias.

47. Alameda: Es uno de los paseos importantes de la capital de la Nueva España para el que se requería ciertos gastos de limpieza, planta de árboles, una cerca perimetral.

48. Garita: en 1767, el visitador pidió a la ciudad que para evitar el mejor funcionamiento de la Real Aduana y evitar el contrabando, se construyera un puente junto a la garita (Pazos y Pérez, 1988, p. 111). 
DON QUIJOTE No dudo ya que en igualdad de efectos un espíritu anima estos proyectos;

SANCHO

de un espíritu sale tanto exceso.

DON QUIJOTE

SANCHO

A espíritu de mierda me huele eso, dispense, su merced, la cortesía, que la atención en esto es porquería.

DON QUIJOTE Al menos no es muy limpio ni muy puro. [fol. 29r]

Ni cristiano, ni justo, ni seguro.

SANCHO

Pues ¿quién es ese espíritu escondido?

No conozco quién es, pero habrá sido

el que influye en obispos y virreyes

y el que al visitador quitó las leyes.

DON QUIJOTE ¿Qué también los obispos han tenido

la culpa en lo que el pueblo ha padecido?

SANCHO

$\mathrm{Y}$ aún por eso me abstengo

de contar otras cosas que retengo

acá para mi sayo,

que no he de ser tan payo

que toque sin refleja lo vedado

y al fin de todo, quede excomulgado.

DON QUIJOTE Tu atención es cristiana y es debida, pero, dime a mí sólo, por tu vida,

eso en que escrupulizas,

que yo te contendré, si te deslizas.

SANCHO

No está el caso, señor, en deslizarme, que no sé si hago bien en declararme.

DON QUIJOTE No puede ser más grave o más odiosa

que lo que has dicho otra cualquier cosa.

SANCHO Es verdad. [fol. 29v]

DON QUIJOTE Pues ¿qué ha habido sacerdote

que no haga lo mejor?

SANCHO

Fuera un guillote ${ }^{49}$,

si de bueno o de malo yo juzgara

sus acciones, ni yo las sindicara.

Contarlas sólo quise, porque dudo

en algunas si pudo o si no pudo.

DON QUIJOTE Di esas cosas, que yo te iré diciendo

sí o no, conforme así las fuere oyendo,

habla, que ya te escucho.

SANCHO Empezaré que en esto no estoy lucho, (sic)

pienso que debo hablar en mi provecho.

DON QUIJOTE Puedes hablar de fuero y de derecho.

SANCHO

Sólo derecho busco en este apuro, que el fuero me lo tengo muy seguro, y pues él por su pie sólo ha venido por él empiezo y su licencia pido.

49. Guillote: «holgazán y desaplicado». (DRAE) 
DON QUIJOTE Tente, que si hablas del obispo santo de la Puebla, no quiero saber tanto.

SANCHO Ésa es mi duda, y no me satisface qué santo pueda ser con lo que hace. [30r]

DON QUIJOTE Esa materia a Dios es reservada, ni me preguntes ni me digas nada.

SANCHO ¿Ni del de acá podré quejarme un poco?

DON QUIJOTE SANCHO ¿No es obispo también? Pues no, tampoco. Pues si de esa materia hablar no puedo, y ya vuestra merced me metió miedo, dejemos el asunto y hablando vamos de distinto punto, bien que en el alma siento enmudecer en lo mejor del cuento, pues faltan religiones, monjas, vida común, varios sermones, clérigos afligidos, desterrados, hacer y deshacer en prebendados; doctrina recogida de por ahora, concilio provincial en que elabora cierto príncipe santo, con porfía, contra la de Jesús, fiel Compañía, pidiendo su extinción; igracias al cielo

DON QUIJOTE que le da tal cuidado y tal desvelo!

SANCHO En el que todos hablan estos días:

DON QUIJOTE El hablar de ese príncipe te apruebo, porque es justo, es afable, es religioso, es noble, distinguido y muy piadoso; y es caballero de San Juan de Malta, pues misterio a este título no falta, si su instituto es defender la iglesia, hoy viene bien, pues tanto se desprecia.

SANCHO Vuesta merced ha dicho ya en instancia cuanto decir pudiera mi ignorancia; y pues ahora comienza a conocerse, y no puede tan breve comprenderse, dejemos el elogio, que ya indicia hasta que el tiempo lo haga de justicia, que otra ocasión que así nos encontremos, de lo que hubiere habido trataremos.

DON QUIJOTE Vete, Sancho, que yo ya me despido y Dios nos acompañe. [fol. 31r]

50. Bucareli: D. Antonio María de Bucareli y Ursúa fue virrey de la Nueva España de 1771 a 1779 . 
SANCHO Así lo pido.

¿va su merced impuesto en el asunto?

DON QUIJOTE No es posible imponerme en tanto punto.

SANCHO

Resuma, su merced, el silogismo

en cada punto y sacará lo mismo,

pues aunque varios son, siempre se infiere

un fin solo de todos, sea el que fuere.

DON QUIJOTE Ese fin es el diablo, mas Dios sabe

cuanto el hombre es y en su malicia cabe, pero somos tan necios, que no vemos que de Dios en él todo dependemos y que por más que el hombre se previene, Dios hace lo mejor cuando conviene, y aunque siempre, piadoso, nos espera, justiciero, no siempre nos tolera.

SANCHO Eso estoy esperando tamañito ${ }^{51}$.

DON QUIJOTE SANCHO Pues, espera, y a Dios.

Dios sea bendito.

Recibido: 15 de febrero de 2011

Aceptado: 18 de octubre de 2011 